\title{
Produção de artigos sobre Logoterapia no Brasil de 1983 a 2012
}

\section{Production of papers about Logotherapy in Brazil from 1983 to 2012}

\author{
Alan da Silva Véras* \\ Faculdade Ruy Barbosa, FRB, Salvador, Bahia, Brasil \\ Nádia Maria Dourado Rocha** \\ Faculdade Ruy Barbosa, FRB, Salvador, Bahia, Brasil
}

\begin{abstract}
RESUMO
Este trabalho é um estudo sobre publicações cientificas em Logoterapia no Brasil. Em 26 de novembro de 2012 lançou-se o termo descritivo "Logoterapia or Viktor Frankl" em duas bases de dados abertas: BSV Psicologia ULAPSI Brasil e no Google Acadêmico. Selecionou-se publicações de periódicos classificados pela CAPES. Identificou-se 51 artigos cujos dados foram tratados no Microsoft Excel. A análise mostrou que: as publicações foram feitas entre 1983 e 2012, em 29 periódicos, em sua maior parte com Qualis A2. A amplitude de variação das páginas foi de quatro a 25, com 11 de média. 28 trabalhos tinham revisão bibliográfica por modalidade de pesquisa, sete pesquisa de campo e seis experimental. O tema mais abordado foi sentido da vida. 38\% dos autores eram de instituições nordestinas, $75 \%$ da área de psicologia e $55 \%$ pós-graduados ou pós-graduandos strictu sensu. O número crescente de publicações aponta o atual interesse dos brasileiros nesta abordagem, porém são poucos os artigos publicados.
\end{abstract}

Palavras-chave: logoterapia, análise existencial, Viktor Frankl.

\begin{abstract}
This research is about Brazilians papers in Logotherapy. In November 26, 2012 was made one search in two open databases (BSV Psicologia ULAPSI Brasil and Google Acadêmico) using the expression "Logoterapia or Viktor Frankl". Were selected papers of journals with evaluation in the CAPES. Was found 51 papers that was analyzed with Microsoft Excel. Was found that: had papers between 1983 and 2012, in 29 journals, frequently classified with Qualis A2. The pages' variation breadth was for four to 25, with 11 by average. 28 papers had bibliography revision how type of research, seven how fieldwork and six how experimental research. The subject most mentioned was meaning of live. $38 \%$ of authors were by nort-east Brazil's institutes, $75 \%$ by field on psychology and $55 \%$ had post graduated or were doing it. Was concluded that there are crescent interest about Logotherapy in Brazil however papers about this subject even are few in this country.
\end{abstract}

Keywords: logotherapy, existential analysis, Viktor Frankl. 


\section{Introdução}

A Logoterapia é uma abordagem psicoterapêutica que surgiu em Viena entre a década de 1920 e 1930, ganhando força após a Segunda Guerra Mundial. Seu mentor foi o judeu austríaco Viktor Emil Frankl (1905 - 1997), psiquiatra, neurologista e filósofo existencialista, que sobreviveu a quatro campos de concentração nazista e após esta experiência fortaleceu, em sua própria existência, a hipótese que usava como base para a prática de sua clínica psicoterápica: que o sentido da vida é um elemento básico para a preservação da saúde mental (Rodrigues, 1991; Frankl, 2008). Para a Logoterapia o ser humano é uma unidade biopsicossocial e espiritual, dotado de liberdade e responsabilidade pelo que faz. Um dos objetivos desta abordagem é ajudar a pessoa a identificar seus valores e a responsabilizar-se perante eles nas mais variadas circunstâncias.

Inicialmente Viktor Frankl denominava sua abordagem como Existenzanalyse. Este termo, porém, foi colocado em segundo plano, para evitar a confusão decorrente da tradução norte americana, já que nos EUA estavam utilizando a mesma expressão, análise existencial, para traduzir tanto Existenzanalyse como Daseinanalise, a abordagem de Ludwig Binswanger (Frankl, 2011). Assim Frankl passou a usar o termo Logoterapia, sendo que esta inclui uma técnica específica para tratar casos de neurose noogênica ${ }^{1}$. Já a análise existencial é a visão de mundo que orienta a psicoterapia como um todo, independente do quadro clínico do paciente. A Logoterapia, que também ficou conhecida como terceira escola vienense de psicoterapia, possui um conjunto de conceitos que se entrelaçam sistematicamente (Pereira, 2012).

Viktor Frankl defendia que toda psicoterapia tem como paradigma uma visão de mundo e de homem, mas que nem sempre as abordagens deixam isso claro (Peter, 1999). Seus livros tem como característica marcante o esclarecimento, em linguagem acessível, de sua postura relativa a esses assuntos. Em primeiro lugar ele se posiciona ao lado de uma ótica não niilista do mundo. E em segundo lugar vê o homem como um ser biopsicosocial e espiritual, capaz de autodeterminar-se, um ser em aberto (Frankl, 2011). De fato, estaria mais próximo do pensamento de Frankl quem falasse em uma análise sobre a existência em vez de uma análise da existência, já que esta é um fenômeno primário e irredutível, impossível de ser decifrada completamente (Frankl, 1976).

Quanto à visão não niilista do mundo Frankl discorda quando alguém afirma que o homem tem que dar sentido às coisas, como se isto fosse uma atribuição humana. Para esse autor o sentido está presente no mundo e as pessoas precisam encontrá-lo (Frankl, 2011). A sucessão de eventos concatena-se em marcha entre causas 
e efeitos que levam o mundo para um destino. Da mesma forma a história de um sujeito tem implicações na vida familiar, que por sua vez reflete-se em instâncias maiores como escola, bairro, cidade, por exemplo. É uma visão sistêmica do mundo, onde as coisas não só estão integradas, tem uma lógica, mas também uma finalidade. Entretanto Frankl não se arrisca a afirmar qual seria a finalidade do mundo. Para ele tal finalidade permanece como uma incógnita para a ciência e um tema de especulação filosófica e teológica (Frankl, 2010a).

Quanto à visão de homem em Frankl destaca-se a idéia sobre o espiritual. Esta é tanto uma parte constitutiva do homem quanto uma manifestação deste (Guberman e Soto, 2006). Do espiritual brota a liberdade para. Esta é contrastada com liberdade de. Para Frankl o homem não é livre das condições biopsicossociais, mas sim para escolher as atitudes que toma perante tais condições (Frankl, 2012). Isso o torna um ser em aberto, um ser de possibilidades. Essa liberdade só é possível por ele ser dotado de Gewissen (consciência ética ou espiritual), que o capacita a identificar valores pessoais e decidir sobre aplicá-los diante das circunstancias da vida. Para Frankl essa Gewissen é uma dimensão que está arraigada no inconsciente, sendo, portanto basicamente não racional, pré-lógica e intuitiva (Xausa, 1986; Frankl, 2007). O ser livre é a marca especifica do ser humano, como ser em potencial. Qualquer leitura do homem somente a partir de suas condições biopsicossociais será parcial e reducionista. Podem refletir estados ou condições nas quais ele se encontra, mas nunca aquilo que ele é ou o que poderá vir a ser.

O homem é um ser no mundo que devido a sua espiritualidade é capaz de encontrar e concretizar valores na relação com este (Frankl, 2011). Já que possui tal capacidade ele não pode eximir-se da responsabilidade pelas escolhas que faz. O que implica em dizer que ele tem uma parcela de contribuição na formação daquilo que é e pela qual é responsável. Assim a liberdade da qual Frankl trata tem como contrapeso a responsabilidade (Frankl, 2005).

Para a Logoterapia outra característica do homem é que ele possui vontade por sentido (Frankl, 1989). Isso acontece em virtude de sua incompletude. Por mais bens, poder, prestígio e prazer que alguém venha a ter, estes por si só não Ihe basta. Não lhe proporcionam homeostase, pois não preenchem a necessidade de sentido, de sorte que a pessoa permanece em vazio existencial. Ainda mais: existem pessoas, que mesmo possuindo tais coisas caem em tédio e depressão, logo tanto na extrema fartura quanto na miséria extrema o homem pode entrar em desespero, chegando a suicidarse. Para Frankl outras formas de expressão de vazio existencial podem ser mascaradas na agressividade e no uso de psicoativos. Por outro lado, Frankl relata que encontrou em seu consultório (e a sua experiência nos campos de concentração também serve de exemplo) 
que, independentemente da situação que se encontre, se alguém achar um sentido para viver será capaz de suportar as mais duras condições de sofrimento (Frankl, 2011).

Para Frankl não se deve perguntar à vida pelo sentido, antes devese responder a ela, pois cada momento carrega em si um valor em potencial. É a vida que pede às pessoas uma implicação. E de forma geral elas respondem criando ou vivenciando. Quando elas sentemse responsáveis por produzir algo no mundo, achando que devem fazer o melhor de si, contribuindo com algo ou alguém, ela encontrou o que Frankl denominou de valor criativo, que se concretiza criando. Em outros momentos as pessoas entregam-se à experiência, admirando uma obra de arte, uma música, uma paisagem ou deleitando-se na presença da pessoa amada. A esses valores Frankl chamou de vivenciais ou experiências (2010a).

Porém, existem circunstâncias em que a pessoa encontra-se muito limitada: como no caso de uma doença, diante da morte ou diante da culpa real de algo que não deveria ter feito. Aqui ela já não pode criar, mudar os fatos ou vivenciar o que gostaria. Ainda assim é possível ter atitudes perante tais situações, aceitando o que não pode mudar e mudando-se perante tais coisas. Para a culpa o arrependimento. Para a morte, em vez de olhar o que se perdeu, olhar para o que já se conquistou ou para o que ainda pode conquistar. No caso da doença ele cita que é necessário que a pessoa seja ajudada a erguer a cabeça, pois, a doença não lhe rouba a dignidade. Para Frankl das categorias de valores esta seria a superior, ele a chama de valores atitudinais (Frankl, 2011).

Desta forma não há situação na vida em que não se possa encontrar um valor: a vida preserva o sentido apesar de tudo. Ainda assim existem pessoas que podem ter dificuldades para identificar valores e essa dificuldades podem levar à um tipo específico de neurose. Para Frankl as neuroses podem ser psicogênicas, quando provenientes de eventos traumáticos; somatogênicas, as que tem origem em distúrbios orgânicos, como por exemplo no mau funcionamento da tireóide; e as noogênicas, aquelas que tem por fundamento a falta de sentido para viver, embora, nem sempre a falta de sentido implique nesse tipo de neurose. Para ele a agressividade, a adiç̧ão e o suicídio podem ser sintomas de uma neurose noogênica (Frankl, 1976).

Frankl foi aprimorando suas ideias ao longo do tempo e muitas foram as suas publicações. As primeiras datam da década de 1920. Nesse período ele mantinha correspondência com Sigmund Freud (19561939), que em 1924 indicou um artigo seu para a Internationale Zeitschriftfür Psychoanályse ${ }^{2}$. Outros dois artigos foram publicados, um 1925 e outro em 1926, na Internationale Zeitschriftfür Individualpsychologie ${ }^{3}$, por indicação do próprio Alfred Adler (18701937) ${ }^{4}$. Em 1926 Frankl passou a usar o termo Logoterapia em suas conferências. Em 1927 aconteceu sua expulsão do grupo de Adler. 
Entre 1927 e 1928 recebeu apoio financeiro para organizar postos de aconselhamento para juventude em Viena, trabalho tão bem sucedido, que em 1927 não houve suicídio entre jovens naquela cidade. Este fato the deu notoriedade internacional o que fez com que ele viesse a receber convites para fazer conferências em outros países da Europa. Em 1933 Frankl passou a usar o termo alternativo Existezanalyse para falar de sua abordagem, que depois foi evitado devido às explicações já apresentadas (Frankl, 2010b).

No período que antecedeu a Segunda Guerra Mundial ele estava escrevendo um livro cujo manuscrito foi confiscado pela Gestapo junto com sua correspondência com Freud (Frankl, 2010b). Após ser libertado do campo de concentração ele pôde reescrever suas ideias em um livro: Ärztliche Seelsorge $(1946)^{5}$. Porém o livro que Ihe trouxe fama mundial foi o da sua experiência no campo de concentração: Ein Psychologerlebt das Konzentrationslager $(1946)^{6}$. Desde então ele escreveu mais de 30 livros e diversos artigos.

A Logoterapia, contudo, não se restringiu ao seu mentor. Ela vem sendo desenvolvida e aplicada em diferentes áreas. A Dra Elizabeth Lukas, por exemplo, tratou de construir uma teoria da personalidade com um olhar da Logoterapia (Frankl, 1976). Os norte americanos foram os primeiros a aplicá-la ao mundo dos negócios, como teoria da motivação (Frankl, 2011). Existem também trabalhos aplicandoa como terapia familiar, em pequenos grupos (Fabry, 1990), ao ambiente hospitalar, à humanização em psiquiatria (Rodrigues, 1995), às organizações em geral (Teixeira e Domenico, 2008) e à educação (Aquino, 2010). Frankl cita estudos, realizados por pesquisadores de países diferentes, que tiveram por base as hipóteses da Logoterapia e buscaram correlacionar a tentativa de suicídio e vazio existencial, uso de drogas e vazio existencial, agressividade coletiva e objetivo comum (Frankl, 1976).

No Brasil a Logoterapia chegou por volta de 1984, ano em que ocorreu o Primeiro Encontro Latino-Americano HumanísticoExistencial: Logoterapia (Xausa, 2012). Desde então já ocorreram seis congressos brasileiros de Logoterapia e Análise Existencial e a abordagem vem ganhando adeptos no país. Cursos de formação foram se estabelecendo no Paraná, Rio Grande do Sul e São Paulo. A pós-graduação latu sensu oferecida pela Sociedade Brasileira de Logoterapia (SOBRAL) foi reconhecida pelo Ministério da Educação. Outros centros de formação apareceram no interior de São Paulo e no Ceará. Na Paraíba a Logoterapia tornou-se opção de ênfase clínica para conclusão do curso de Psicologia da UEPB, linha de pesquisa no Mestrado em Ciências da Religião da UFPB e expandiu-se para Maceió - AL e São Luís - MA, onde foi criado o Instituto Geist (Germano, 2012).

Cabe frisar aqui a existência dos seguintes centros ligados à Logoterapia: Associação Brasileira de Logoterapia (ABLAE) e a 
Associação de Logoterapia Viktor Frankl (ALEVF) em Curitiba - PR, Associação Pernambucana de Logoterapia (APELO) em Recife - PE, Centro Viktor Frankl de Logoterapia e o Curso de Pós-graduação em Análise Existencial em Porto Alegre - RS, a SOBRAL em São Paulo - SP, o Colégio Viktor Frankl em Ribeirão Preto - SP, o Grupo de Estudos Viktor Emil Frankl em Campinas (GEVEF) - SP, Faculdade Católica Rainha do Sertão em Quixadá - CE, Núcleo Viktor Frankl em Campina Grande - PB e o Grupo de Pesquisa Nous: Espiritualidade e Sentido da UFPB.

Ainda sobre os espaços ocupados pela Logoterapia no Brasil convém ressaltar que, coforme Xausa (2012), quando da fundação da Sociedade Brasileira de Logoterapia (SOBRAL) e da Sociedade LatinoAmericana de Logoterapia (SOLAL), em 1984, ficou estatutariamente decidido que a cada dois anos a SOLAL seria sediada em um país membro diferente e que, pelo mesmo período, a SOBRAL faria a rotatividade da sede entre os estados-membros. Assim nos anos 1984 e 1985 a sede da SOBRAL esteve em Porto Alegre - PR, de 1986 e 1987 em Brasília- DF, de 1988 e 1999 em Belo Horizonte MG, de 1990 a 1993 em São José dos Campos - SP e desde então em São Paulo, capital. É possível que, após estabelecer-se em São Paulo, a falta de rotatividade da sede da SOBRAL tenha atrasado a disseminação da abordagem em outros estados. Além disso, as palavras de Xausa parecem indicar algum desentendimento entre os pioneiros da Logoterapia aqui no Brasil:

"A SOLAL cumpriu sua regimental e, após algum tempo, foi para Buenos Aires e a SOBRAL passou por Brasília, Minas Gerais e São Paulo. Ignoro os motivos por que ambas as sociedades não mais cumpriram essa norma estatutária e se fixaram, a primeira, em Buenos Aires e a segunda, em São Paulo". (Xausa, 2013, p.83).

Temos que levar em conta o peso dessa queixa, pois, afinal, Izar Xausa foi umas das principais responsáveis pela vinda de Viktor Frankl ao Brasil, a primeira presidente da SOLAL e uma disseminadora da Logoterapia em Porto Alegre - RS, na Paraíba, em Fortaleza - CE, em Salvador - BA, em Curitiba - PR (Xausa, 2012). Portanto, a queixa parece indicar uma possível divisão entre os grupos que foram se formando e isso pode ter implicado em um algum obstáculo para uma disseminação mais rápida da Logoterapia no Brasil. Nesse sentido a criação da ABLAE, em 2010, parece ser uma tentativa de atacar esse problema, pois traz propostas que resgatam as idéias colocadas quando da formação da SOBRAL (ABLAE, 2011) ${ }^{7}$.

Quanto às publicações nacionais sobre a Logoterapia no Brasil os primeiros artigos datam de 1983. Desde então alguns estudos 
foram desenvolvidos. Dentre eles estão os que correlacionam atitude religiosa e sentido da vida (Aquino, Correia, Marques, Souza, Freitas, Araújo, Dias, Araújo, 2009), sentido da vida e estresse entre professores (Silva, Damasio \& Melo, 2009), resiliência e sentido da vida (Moreira \& Holanda, 2010), etc. Entretanto, nem sempre é fácil localizar esses trabalhos. Pois, além de poucos, eles encontram-se dispersos em vários periódicos nas diferentes regiões do país.

Esta pesquisa teve por objetivo estudar a produção de trabalhos com orientação em Logoterapia produzidos no Brasil. Buscou-se arrolar todos os artigos indexados em duas bases de dados abertas, BVS$\mathrm{Psi}^{8}$ e no Google Acadêmico, publicados em revistas identificadas por ISSN e qualificadas pela CAPES. Buscou-se verificar a quantidade de artigos produzidos, sua periodicidade, os autores, sua formação e instituições, os periódicos em que os artigos foram publicados, a classificação desses periódicos na CAPES, a quantidade de páginas dos artigos, a modalidade de pesquisa e as temáticas abordadas.

\section{Metodologia}

\subsection{Procedimento para coleta de dados}

A busca de artigos foi realizada no dia 26 de novembro de 2012, utilizando-se o termo descritor "Logoterapia or Viktor Frankl". Foram selecionados artigos com ISSN e qualificação junto à CAPES, com exceção da Revista Logos \& Existência (ISSN 2316-9923), pois tratase de um periódico exclusivo para publicações em Logoterapia cuja primeira edição ocorreu em novembro de 2012. Foram identificadas 51 publicações ${ }^{9}$.

\subsection{Procedimento para análise de dados}

Foram inseridos em planilha do Microsoft Excel informações sobre as seguintes variáveis: autor e co-autor (es), instituição destes e a respectiva Unidade da Federação, título, periódico, ano, Qualis, número de páginas, modalidade de pesquisa e assunto. Esses dados foram cruzados em tabelas dinâmicas e analisados.

\section{Resultados}

\subsection{Artigos publicados por década}

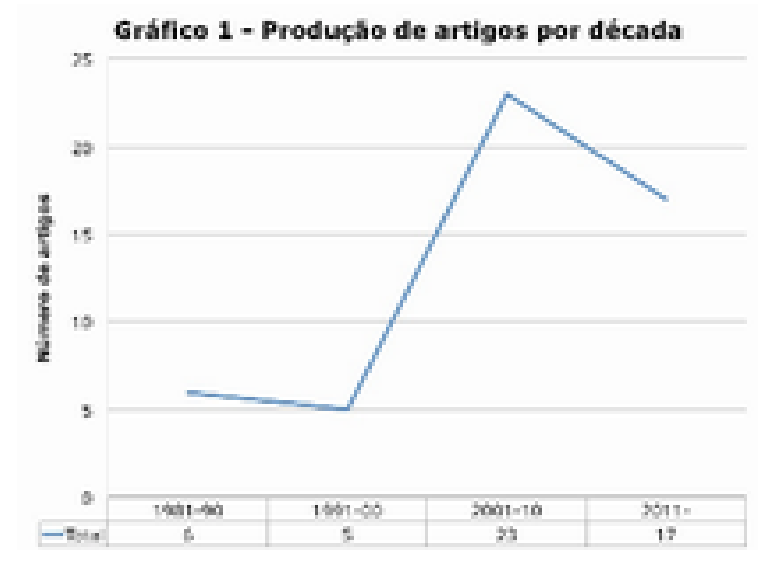


Os 51 artigos foram publicados entre 1983 e 2012. No Gráfico 1 nota-se a distribuição dos artigos por década. Tem-se a seguinte configuração: nas décadas de 80 e 90 a proporção foi de menos de um artigo por ano, pois encontrou-se seis artigos publicados entre 1983 e 1990 e cinco entre 1991 e 2000 . Na década seguinte esse quadro começou a mudar, pois, com 23 artigos encontrados entre 2001 e 2010, a proporção ficou de mais de dois artigos por ano. O Gráfico 1 ainda mostra que nos dois últimos anos (2011 e 2012) a média de artigos encontrados subiu para a proporção mais de oito artigos por ano. Se é correto dizer que os artigos encontrados refletem a proporção de publicações na área, e se isso reflete uma tendência, a probabilidade é que esta década supere a anterior em número de publicações.

\subsection{Publicações por região}

Verificou-se que os artigos foram produzidos por autores de 28 instituições do Brasil ${ }^{10}$, sendo que a Região Norte (NO) foi a única que não apareceu11. Além disso, dois trabalhos foram feitos por autores de instituições estrangeiras ${ }^{12}$. 0 Gráfico 2 apresenta em números de porcentagem os artigos encontrados conforme a localização da instituição.

É possível notar que a maior parte das publicações encontradas é de instituições que se concentraram em três regiões: Nordeste, Sul e Sudeste. A Região que possui a maior parte das publicações encontradas é a Nordeste (NE), com $38 \%$ dos artigos. Tanto a Região Sul (SS) como a Sudeste (SE)

Gráfico 2 - ProduçJ̃o por regīào

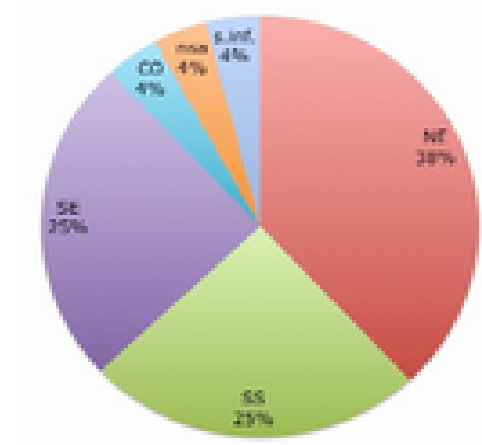
apareceram com $25 \%$ do total. A região Centro-Oeste (CO) teve quatro por cento. O Gráfico também indica artigos que não se aplicam (nsa) a autores de instituições brasileiras e outros cujas que não foram acessados na integra (s. inf.).

Entre os artigos produzidos por autores vinculados a instituições do Nordeste dez foram da Paraíba, Estado que teve o maior número das produções encontradas, quatro do Ceará, três da Bahia, um de Sergipe e um de Pernambuco. Sobre os artigos da região Sul, oito foram de autores vinculados a instituições do Rio Grande do Sul e cinco do Paraná. Sobre os do Sudeste, seis foram de autores vinculados a instituições de São Paulo, seis de Minas Gerais e um do Rio de Janeiro. Os dois artigos achados da região Centro Oeste originaram-se de autores de instituições do Mato Grosso do Sul.

\subsection{Trabalhos individuais e com parceria}


O Gráfico 3 apresenta os artigos feitos por somente um autor. Vinte e seis se nesta condição, perfazendo um total artigos achados nesta pesquisa. foram identificadas, nove delas artigo. A Universidade Federal do Rio destacou-se com cinco trabalhos. Em possível identificar a instituição a que No Gráfico 4 tem-se uma representação autores tiveram parceria unicamente instituição. Entre os artigos que se encontravam nessas condições os da Universidade Estadual da Paraíba (UEPB) de co-autorias (sete), acompanhados dos da Paraíba (UFPB), com seis, e os da Minas Gerais (UFMG), com três.

A Gráfico 5 representa os trabalhos cujos tiveram, ao mesmo tempo, parceiros interinstitucional. Duas Instituições de iveram trabalhos que se encontravam nessas condições: a UFPB e a Universidade Estadual de Feira de teve uma co-autoria interinstitucionais e sendo três da UEPB e uma com a Sergipe (UFSE). Já a UEFS teve uma coe uma com a Universidade Estadual do O Gráfico 6 representa os trabalhos cujas unicamente interinstitucional. A Rainha do Sertão (FCRS) teve um da Faculdade Metropolitana da Grande duas da UECE; a UFSE teve um artigo UFRGS e uma da UEPB; a Centro Ometto (UNIARARAS) teve um artigo Universidade de Campinas (UNICAMP) e do Mato Grosso do Sul (UFMS) teve uma autoria da Escola de Enfermagem da Paulo (EEUSP).

Em um trabalho com co-autoria não foi possível identificar a(s) instituição(ões) a que pertencia(m) os autores.

\subsection{Autores, co-autores e número de páginas dos artigos}

Os artigos foram produzidos por 87 pessoas, das quais 40 apareceram como autores principais e 47 como co-autores. Vinte e seis artigos foram produções individuais, um teve sete co-autores, 
dois seis, um quatro, dois três, cinco dois e 16 um. Dentre autores e co-autores o que mais aparece é Tiago Aquino (UEPB/UFPB), com sete produções, seguido de Paulo Kroeff (UFRGS), com três.

Quanto à formação dos autores, quando da publicação dos artigos, constatou-se que 26 possuíam doutorado, dois eram doutorandos, oito mestres, 11 mestrandos, 17 graduados e 16 graduandos. No Gráfico 7 é possível conferir a área de formação dos autores: 46 eram psicólogos, 16 eram estudantes de psicologia (Est. Psi.), 11 eram formados em enfermagem, seis em teologia, cinco em filosofia e quatro em medicina. Havia um autor com formação em administração, mesmo número dos formados ciências sociais, ciências da religião, direito, engenharia química, pedagogia, sistema de informação ou era graduando em teologia. Não foi possível obter informações referentes à formação de seis autores quando da publicação dos seus trabalhos.

A amplitude de variação das páginas dos artigos ficou entre quatro e 25 , sendo a média e a mediana 11 e a moda 12 . O Gráfico 8 mostra a distribuição dos artigos conforme o total das páginas. Verifica-se que quatro tinham entre 21 e 25 páginas, três entre 16 e 20, vinte e um entre 11 e 15, vinte e um entre seis e 10 e três tinham até cinco páginas.

\subsection{Publicações por periódicos}

Até o ano de 2012 não existia, para publicações sobre Psico de Porto Alegre já havia português, sendo, até então, as revista acessadas, a que tinha publicações sobre esta

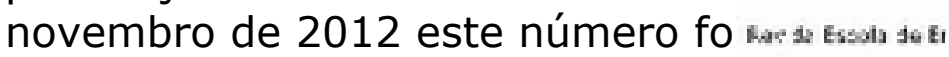

Gráfico 9 - Publicaçōes por periódico Logoterapia, a Logos \& apareceu como um periódico abordagem. No Gráfico 9 é número de publicações por Constata-se certa dispersão das Logoterapia. Os cinqüenta e dois artigos estão distribuídos em vinte e nove vinte e duas delas publicaram somente um

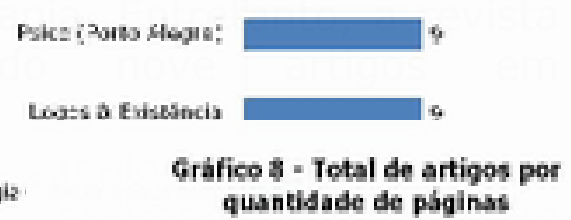
quantidade de phginst (n)

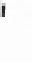
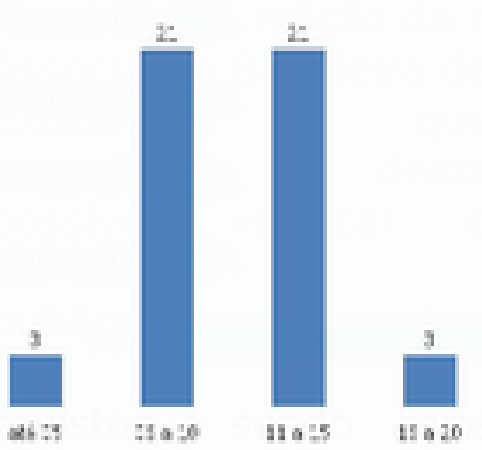

trabalho ${ }^{14}$. Dentre as revistas acessadas, além de Logos \& Existência e Psico (Porto Alegre), outras cinco publicaram mais de um artigo: Psicologia Ciência e Profissão, com três artigos, Informação Psiquiátrica, Psicologia, Revista Baiana de Enfermagem e a Revista da Escola de Enfermagem da USP, com dois artigos cada. 
Em relação a avaliação reconhecida pela CAPES, quanto à qualidade dos periódicos em que estavam divulgados os artigos, achou-se que: um artigo estava publicado em revista classificada como de Qualis $A 1$, dezesseis em $A 2$, quatro em $B 1$, onze em $B 2$, uma em $B 3$, uma em B4 e cinco em B5. Não foi possível identificar a avaliação de três publicações: duas da Informação Psiquiátrica, um de 1993 e outro de 1996, além de um artigo da Psique de 1999. A revista Logos \& Existência, que continha nove artigos em português, também não pode ser classificada, pois, conforme já foi dito, tinha lançado sua primeira edição em novembro de 2012, mesmo mês em que foi realizada esta pesquisa.

\section{Modalidade de pesquisa e assuntos}

Quanto à modalidade de pesquisa identificou-se que 28 trabalhos eram de revisão bibliográfica, sete de pesquisa de campo e seis de pesquisa experimental, nove trabalhos não puderam ser acessados na íntegra, não sendo possível identificar esses dados metodológicos. Os títulos dos artigos apresentaram temáticas variadas. O assunto mais frequente foi Sentido da Vida, sendo que o termo sentido apareceu também nas expressões sentido do sofrimento, sentido do cuidar e vontade de sentido. Vinte e três artigos tinham seus títulos vinculados ao tema saúde, sendo mais recorrentes assuntos da área de saúde mental, com seis referências. Outros assuntos ligados à área de saúde foram: dependência química, resiliência, vazio existencial, ansiedade, câncer, estresse, grupos de auto-ajuda, nutrição, pacientes em estado terminal, psicoterapia e UTI.

Assuntos ligados às fases do desenvolvimento apareceram oito vezes nos títulos dos artigos: dois artigos tratavam diretamente do desenvolvimento na terceira idade, um na fase adulta e um na infância. Temas ligados a relacionamento surgiram oito vezes, foram eles: amor, relacionamento, sociabilidade, sexualidade e família.

Assuntos relacionados à educação e criatividade apareceram cinco vezes. Ligados ao trabalho, três vezes, foram eles: desemprego, trabalho e significado da personalidade profissional.

Sete títulos remetiam à religião e dois à espiritualidade.

Outros temas foram: antropologia, autodistanciamento, biografia, campos de concentração, consumação do vazio, consumismo, consumo, ética, felicidade, finitude, homo humanus, humanismo, liberdade, lingüística, moralidade, mundo, necessidades especiais, pós-modernidade, revisão bibliográfica, verdade do ser, violência, visão de homem e um artigo tratava da relação entre as ideias de Viktor Frankl com as de Xavier Zubiri. 


\section{Considerações finais}

A Logoterapia chegou ao Brasil por volta de 1984, ano em que ocorreu o Primeiro Encontro Latino-Americano HumanísticoExistencial: Logoterapia. Desde então já ocorreram seis congressos brasileiros de Logoterapia e Análise Existencial, a abordagem ganhou adeptos no país, o curso de especialização foi reconhecido junto ao MEC e a disciplina entrou em universidades. Estes fatos possivelmente estão relacionados ao maior número de artigos ligados a essa abordagem nos últimos anos. Apontam também para uma tendência desta década em superar, de forma vertiginosa, as anteriores no que diz respeito ao número de publicações. Em dois anos, foram publicados um número médio de artigos que ultrapassou as publicações das décadas passadas.

Quanto às regiões, ganha destaque a Nordeste, com o maior número de publicações. Um fato raro dentro do contexto da Psicologia brasileira. Nessa região destacam-se as instituições da Paraíba, tanto pelo número de produções quanto pelo de parcerias estabelecidas.

Entretanto, convém apontar que a produção de artigos, localizada nas referidas fontes, ainda é pequena e com um baixo número de páginas, muito embora uma grande parte destas publicações pertençam a periódicos classificados dentro do padrão Qualis A2. Portanto, notamos que a maior parte dessas publicações é de revisão bibliográfica e trata do sentido da vida. Faltam estudos de campo e pesquisa experimental. Além disso, existe uma descontinuidade nas linhas de pesquisa e poucos autores com mais de um trabalho. Um pouco mais da metade dos artigos são produções individuais, o que pode apontar para a necessidade de estabelecimento de vínculo entre pessoas e instituições para a transmissão de saber. Dos autores apontados, apenas Thiago Aquino (UEPB e UFPB), parece estar mais envolvido com pesquisa experimental e publicação. Esses fatos levam a pensar que a abordagem ainda está em fase de implantação e amadurecimento no Brasil, que faz-se necessário o desenvolvimento de estudos mais duradouros que mostrem como a abordagem vem sendo aplicada no País e os resultados que vem sendo alcançados.

Dos 87 autores, 26 possuíam doutorado, dois eram doutorandos, oito mestres, 11 mestrandos, perfazendo um total de $55 \%$ de autores em posição de destaque entre graduados. Isso pode resultar em uma influência positiva em relação à abordagem e a possibilidade de novas linhas de pesquisa. Ademais, nota-se que a abordagem desperta o interesse de profissionais de campos diversos, seja os da área de humanas, destacando-se filósofos, teólogos e pedagogos ou da área da saúde como psicologia, enfermagem e medicina, mostrando o campo de possibilidades que existe para ser explorado. Quanto à dispersão de publicações é possível que essa tendência diminua e que elas passem a ser concentradas na Revista Logos \& 
Existência, da Associação Brasileira de Logoterapia.

Esses dados, quando lidos a partir de uma perspectiva da história do movimento da Logoterapia no país, levam a acreditar que o possível desentendimento entre os pioneiros teria levado-os a focar a atenção em outras questões que não a produção de publicações científicas. Assim a região Sul e Sudeste, que historicamente abrigou a maior parte dos centros de formação, e onde a SOBRAL se estabeleceu, deixou de publicar o tanto quanto poderia se esperar por parte deles. Esses dados também poderiam explicar o porquê da dispersão das publicações, o motivo de mais de $50 \%$ delas ser trabalho individual e também a razão da pequena expressividade de publicações até o ano de 2008.

Por outro lado, o grupo que instalou-se no Nordeste, tendo personalidades ocupando lugar de destaque nos cursos de psicologia da Paraíba (como Gutemberg Germano que tornou-se coordenador na UEPB), conseguiu exercer maior influência sobre os alunos, dedicar-se à pesquisa, estabelecer parcerias e produzir, nos últimos anos, mais publicações que o grupo do sulista. Deve-se acrescentar também que o reconhecimento do curso de pós-graduação junto ao MEC pode ter sido um fator que despertou para a necessidade de publicar, levando os estudiosos a esforçarem-se nesse sentido.

Para finalizar gostaríamos de apontar alguns limites desta pesquisa e sugerir campos a explorar em novos estudos. Como a busca restringiu-se a duas bases de dados abertas (BVS e Google Acadêmico), um novo estudo poderia explorar outras bases de dados como forma de ampliar o espectro da busca. A pesquisa identificou, mas não incluiu artigos em outras línguas publicados em periódicos brasileiros, esse dado poderia ser acrescentado em um novo trabalho. Outra sugestão seria explorar as fontes de base utilizadas em cada artigo, a fim de verificar como se delineia a genealogia intelectual dos autores em suas publicações.

\section{Referências}

Associação Brasileira de Logoterapia e Análise Existencial (2013). Estatuto Social. Recuperado em: 18 Out. 2013 de <http://espiritualidadesentido.yolasite.com/resources/ ESTATUTO\%20ABLAE.pdf>. Curitiba.

Associação Brasileira de Logoterapia e Análise Existencial (2011). Boletim Informativo da ABLAE (n. 01 - Ano 1, 04 de agosto de 2011). Recuperado em: 18 Out. 2013. de: <http://espiritualidadesentido.yolasite.com/resources/

Boletim\%2001\%20-\%2004\%20AGO\%202011.pdf>.

Aquino, T. A. A. de, Damásio, B. F. \& Silva, J. P. (Orgs.) (2010). Logoterapia \& Educação. São Paulo: Paulus. 
Aquino, T. A. A. de , Correia, A. P. M., Marques, A. L. C., Souza, C. G. de, Freitas, H. C. de A., Araújo, I. F. de, Dias, P. dos S. \& Araújo, W. F. de (2009). Atitude religiosa e sentido da vida: um estudo correlacional. Psicologia, Ciência e Profissão, 29(2), 228-243.

Fabry, J. (1990). Aplicações práticas da Logoterapia. São Paulo: Cultura Espiritual.

Frankl, V. E. (2012). Logoterapia e análise existencial: textos de seis décadas. Rio de Janeiro: Forense Universitária.

Frankl, V. E. (2011). A vontade de sentido: fundamentos e aplicações da Logoterapia. São Paulo: Paulus.

Frankl, V. E. (2010a). Psicoterapia e sentido da vida. São Paulo: Quadrante.

Frankl, V. E. (2010b) O que não está escrito em meus livros: memórias. São Paulo: É Realizações.

Frankl, V. E. (2008). Em busca de sentido: um psicólogo no campo de concentração. São Leopoldo: Sinodal; Petrópolis: Vozes.

Frankl, V. E. (2007). A presença ignorada de Deus. São Leopoldo: Sinodal; Petrópolis: Vozes

Frankl, V. E. (2005). Um sentido para a vida: psicoterapia e humanismo. Aparecida: Ideias \& Letras.

Frankl, V. E. (1989). Sede de sentido. São Paulo: Quadrante.

Frankl, V. E. (1976). A psicoterapia na prática. São Paulo: Pedagógica e Universitária.

Germano, G. (2012). A Logoterapia no Nordeste: a história dos 29 do Núcleo Viktor Frankl em Campina Grande-PB. Recuperado em 18 Out. 2013, de <http://www.youtube.com/watch?v=WUWSIgij6xI>

Guberman, M. \& Soto, E. P. (2006). Dicionário de Logoterapia. Lisboa: Paulus.

Moreira, N. \& Holanda, A. (2010). Logoterapia e o sentido do sofrimento: convergências nas dimensões espiritual e religiosa. PsicoUSF, 15(3), 345-356.

Pereira, I. S. (2012). A ética do sentido da vida: fundamentos filosóficos da Logoterapia. Aparecida: Idéias\& Letras.

Peter, R. (1999). Viktor Frankl: a antropologia como terapia. São Paulo: Paulus.

Rodrigues, R. (1995) Fundamentos da Logoterapia: na clínica psiquiátrica e psicoterapêutica. (v. II). Petrópolis: Vozes.

Rodrigues, R. (1991). Fundamentos da Logoterapia: na clínica psiquiátrica e psicoterapêutica (v. I). Petrópolis: Vozes, 1991.

Silva, J. P., Damasio, B. F. \& Melo S. A. (2009). O sentido de vida e o estresse do professorado: um estudo correlacional. Cadernos de psicologia social do trabalho, 12(1), 111-122.

Teixeira, M. L. M. \& Domenico, S. M. R. de. (2008). Gestores brasileiros e portugueses: Estrutura única de valores de sentido de vida?. Comportamento Organizacional e Gestão, 14(1), 45-64. 
Xausa, I. A. de M. (2012). Viktor Frankl entre nós: a história da Logoterapia no Brasil e integração pioneira da Logoterapia na América Latina. Porto Alegre: EDIPUCRS.

Xausa, I. A. de M. (1986). A psicologia do sentido da vida. Petrópolis: Vozes.

\section{Endereço para correspondência \\ Alan da Silva Véras}

Esquadrão de Polícia Montada da PMBA

Pq. de Exposições Agropecuárias, Av. Dorival Cayme, s/n. Itapuã, CEP 41180-620, Salvador - BA, Brasil.

Endereço eletrônico: alanveras@gmail.com

\section{Nádia Maria Dourado Rocha}

Faculdade Ruy Barbosa

R. Theodomiro Baptista, 422, Rio Vermelho, CEP 41940-320, Salvador - BA, Brasil. Endereço eletrônico: nrocha@frb.edu.br

Recebido em: 11/06/2013

Reformulado em: 17/10/2013

Aceito para publicação em: 26/10/2013

Acompanhamento do processo editorial: Ana Maria Jacó-Vilela

\section{Notas}

* Formado em Psicologia pela Faculdade Ruy Barbosa e aluno especial do mestrado em Psicologia da Universidade Federal da Bahia - Salvador (BA), Brasil. Trabalha no Esquadrão de Polícia Montada da Polícia Militar da Bahia - PMBA.

** Psicóloga, doutora em Psicologia; docente da Faculdade Ruy Barbosa - Salvador (BA), Brasil.

${ }^{1}$ Explicada mais adiante.

2 Revista Internacional de Psicanálise

3 Revista Internacional de Psicologia Individual

4 Nesse período Frankl fazia parte do grupo de Alfred Adler.

5 Traduzido em português pela editora Quadrante com o título Psicoterapia e Sentido da Vida.

6 Traduzido em português pelas editoras Vozes e Sinodal com o título Em busca de sentido: um psicólogo no campo de concentração.

7. Conferir também o Art. $3^{\circ}$ do Estatuto Social da ABLAE: "A Associação Brasileira de Logoterapia e Análise Existencial - ABLAE tem sede e foro jurídicos em Curitiba, Capital do Estado do Paraná e sede administrativa itinerante, localizando-se, a cada dois (2) anos, preferencialmente na cidade da residência e do domicílio do Presidente, ou na cidade que a diretoria eleita julgar mais conveniente para suas reuniões, em cada biênio".

8. A BVS-Psi integra as seguintes bases de dados: Rede SciELO (Scientific Electronic Library Online); Rede ScienTI (Rede Internacional de Fontes de Informação e de Conhecimento para a Gestão de Ciência, Tecnologia e Inovação); Rede ePORTUGUÊSe (Rede de Fontes de Informação e Conhecimento em Saúde para os Países de Língua Portuguesa); GHL (Global Health Library); e TropIKA.net (Tropical Diseases Research to Foster Innovation and Knowledge Application); EVIPNet (Evidence-informed Policy Networks).

9 A lista completa consta no apêndice.

10 São elas: Associação Brasileira de Logoterapia e Análise Existencial - PR (ABLAE); Centro Universitário Newton Paiva - MG (CUNP); Escola de Enfermagem da Universidade de São Paulo (EEUSP); Faculdade Metropolitana da Grande 
Fortaleza (FAMETRO); Faculdade Católica Rainha do Sertão (FCRS); Instituto Federal de Educação, Ciência e Tecnologia - PB (IFPB) Pontífica Universidade Católica de Campinas - SP (PUCCAMP); Pontifica Universidade Católica - MG (PUCMG); Pontifica Universidade Católica - PR (PUC-PR); Pontifica Universidade Católica - RS (PUC-RS); Universidade Católica Dom Bosco - MS (UCDB); Universidade de Caxias do Sul - RS (UCS); Universidade Estadual do Ceará (UECE); Universidade Estadual da Paraíba (UEPB); Universidade Estadual de Feira de Santana - BA (UEFS); Universidade Federal da Bahia (UFBA); Universidade Federal do Ceará (UFCE); Universidade Federal de Minas Gerais (UFMG); Universidade Federal do Mato Grosso do Sul (UFMS); Universidade Federal da Paraíba (UFPB) Universidade Federal do Paraná (UFPR); Universidade Federal do Rio Grande do Sul (UFRGS); Universidade Federal do São Carlos - SP (UFSCar); Universidade Federal do Sergipe (UFSE); Centro Universitário Hermínio Ometto - SP (UNIARARAS); Universidade Estadual de Campinas - SP (UNICAMP); Universidade Católica de Pernambuco (UNICAP); Universidade de São Paulo (USP).

11. Não foi possível acessar esses dados de cinco artigos.

12. Alemanha e Itália

13. Instituição de Ensino Superior

14 São elas: Cadernos de Psicologia Social do Trabalho, Estudos, Estudos Avançados, Estudos de Psicologia, Estudos de Religião, Ideação, Interação em Psicologia, Jornal Brasileiro de Psiquiatria, Memorandum, Psico(Usf), Psicologia Argumento, Psicologia da Educação, Psicologia em Estudo, Psicologia: Reflexão e Crítica, Psique, Revista Abordagem Gestaltica, Revista da Rede de Enfermagem do Nordeste, Revista Educação Especial, Revista Eletrônica Espaço Teológico, TEMA Revista Eletrônica de Ciências, Teocomunicação e Terapia Sexual.

\section{Apêndice - Lista completa das publicações encontradas}

1. Albertini, R. Z. (2010). O homem capaz de Deus: perspectivas de Viktor Frankl e do catecismo. Revista Eletrônica Espaço Teológico, 4(5), 62-70. Recuperado em 29 nov. 2012, de: <http://revistas.pucsp.br/index.php/reveleteo/article/view/3465/ 2289>.

2. Albuquerque, L. A; Nascimento, M. A. \& Jorge, M S. B. (2004/2005.). Sentido da vida para o cliente com câncer: uma abordagem, existencial humanista. Revista Baiana de Enfermagem, 19,20 (1,2,3), 31-41. Recuperado em 29 nov. 2012, de: <http://www.portalseer.ufba.br/index.php/enfermagem/article/view/3887/2851>. 3. Amorim, H. K. \& Amatuzzi, M. M. A. (2011). Vivência comunitária católica e crescimento pessoal. Psico, 42(3), 393-411 . Recuperado em: 29 nov. 2012, de: $<$ http://revistaseletronicas.pucrs.br/ojs/index.php/revistapsico/article/viewFile/ 6524/6995>.

4. Aquino, T. A. A. (2012) O latim na obra de Viktor Frankl e suas implicações teóricas. Logos \& Existência, 1(1), 65-71. Recuperado em 29 nov. 2012, de: <http://www.ies.ufpb.br/ojs/index.php/le/article/view/12932>.

5. Aquino, T. A. A.; Silva, J. P.; Figueirêdo, A. T. B.; Dourado, É. T. S. \& Farias E. C. S.(2011). Avaliação de uma proposta de prevenção do vazio existencial com adolescentes. Psicologia: Ciência e Profissão, 31(1), 146-159. Recuperado em: 29 nov. 2012, de: <http://www.scielo.br/scielo.php?script=sci_arttext\&pid=S141498932011000100013\&lng=en\&nrm=iso > .

6. Aquino, T. A. A.; Correia, A. P. M.; Marques, A. L. C.; Souza, C. G; Freitas, H. C.; Araújo, I. F.; Dias, P. S. \& Araújo, W. F. (2009). Atitude religiosa e sentido da vida: um estudo correlacional. Psicologia: Ciência e Profissão, 29(2), 228243.Recuperado em 29 nov. 2012, de: <http://www.scielo.br/scielo.php? script $=$ sci_arttext\&pid=S1414-98932009000200003\&lng =en\&nrm=iso $>$.

7. Aquino, T. A. A.; Serafim, T. D. B.; Silva, H. D. M. Da; Barbosa, E. L.; Cirne, E. de A.; Ferreira, F. R. \& Dantas, P. R. S.(2010). Visões de morte, ansiedade e 
sentido da vida: Um estudo correlacional. Psicologia Argumento, 28(63), 289-302. Recuperado em: 29 nov. 2012, de:<http://espiritualidadesentido.yolasite.com/ resources/Morte\%20Ansiedade\%20e\%20Sentido.pdf >.

8. Aquino, T. A A.; Gouveia, V. V.; Patrício, K. S. C.; Silva, M. G. S.; Bezerra, J. L. M.; Souza Júnior, V. B. \& Oliveira Neto, W. M. (2012). O amor entre jovens em tempos de ficar: correlatos existenciais e demográficos. Psicologia: Ciência e Profissão, 32(1), 112-125. Recuperado em 29 nov. 2012, de:<http://www.scielo.br/scielo.php?script=sci_arttext\&pid=S141498932012000100009\&lng=en\&nrm =iso $>$.

9. Aquino, T. A. A.; Fernandes, A. S. \& Pereira, G. de A. (2012). Do Sagrado de Eliade ao Logos de Frankl: um estudo comparativo. Estudos de Religião, 26(42), 119-133. Recuperado em 29 nov. 2012, de:<https://www.metodista.br/revistas/ revistas-ims/index.php/ER/article/view/2945/3092>.

10. Aquino, T. A. A; Alves, A. C. D; Aguiar, A. A. \& Refosco, R. F. O. (2010). Sentido da vida e conceito de morte em estudantes universitários: um estudo correlacional. Interação em Psicologia, 14(2), 233-243. Recuperado em 29 nov. 2012, de: <http://ojs.c3sl.ufpr.br/ojs2/index.php/psicologia/article/view/16696/ 13924>. Araújo, M. A. M.; Moreira, K. A. P.; Silveira, L. C. \& Braga V. A. B. (2008). A logoterapia e suas relações com os cuidados de enfermagem em saúde mental. Revista da Rede de Enfermagem do Nordeste, 9(4), 158-164. Recuperado em: 29 nov. 2012, de: <http://www.revistarene.ufc.br/vol9n4_pdf/a19v09n4.pdf>. 11. Brandalise, M. H. \& Brás, A. L. N. (2011). A visão da sexualidade e sentido de vida à luz da teoria de Viktor E. Frankl. Terapia Sexual, XIV(2), 93-99. Recuperado em 29 nov. 2012, de: <http://psicologia.inpasex.com.br/wp-content/uploads/ revistas_ts_pdf/rtsXIV22011.pdf\#page $=93>$.

12. Caldas, M. T. \& Calheiros, M. E. (2012). Homo humanus à luz da Verdade do Ser e do Sentido da Vida: O pensamento de Martin Heidegger e de Viktor Frankl acerca da Humanitas. Logos \& Existência, 1(1), 88-99. Recuperado em 29 nov. 2012, de: <http://www.ies.ufpb.br/ojs/index.php/le/article/view/14082/8069>.

13. Carvalho, J. M. R. (1993). O vazio existencial e o sentido da vida. Informação Psiquiátrica, 3(12), 111-115.

14. Coelho Junior, A. G. \& Mahfoud, M. (2001). As dimensões espiritual e religiosa da experiência humana: distinções e inter-relações na obra de Viktor Frankl. Psicol. USP, 12(2), 95-103. Recuperado em 29 nov. 2012, de: $\quad<$ http://www.scielo.br/scielo.php?script=sci_arttext\&pid=S0103$65642001000200006 \&$ lng $=$ en\&nrm $=$ iso $>$.

15. Faingluz, M. E. W. (1989). Do criativo ao sentido. Psico, 17(1), 108-122.

15. Garcia, S. C. (2008). A resiliência no indivíduo especial: uma visão logoterapêutica. Revista Educação Especial, 21( 31), 25-36. Recuperado em 29 nov. 2012, de: <http://cascavel.ufsm.br/revistas/ojs-2.2.2/index.php/ educacaoespecial/article/view/7/19>.

16. Godoy, R. F. (1996). O vazio existencial e sua relação com a dependência química. Informação Psiquiátrica, 2(15), 46-49.

17. Guareschi, P. (1984). Apreciação da obra de Viktor Frankl. Psico (Porto Alegre), 8(1), 19-29.

18. Guedes, K. C. \& Gaudêncio, E. O. (2012). Trabalho e logoteoria: análise existencial da situação de desemprego. Logos \& Existência, 1(1), 26-37. Recuperado em 29 nov. 2012, de: <http://www.ies.ufpb.br/ojs/index.php/le/ article/view/12569/8063>.

19. Guimarães, A. G. C. \& Moreira, J. O. (2011). A religiosidade do morador de rua e o sentido de vida: o caso Marcelo. Memorandum, 20, 225-249. Recuperado em 29 nov. 2012, de: <http://www.fafich.ufmg.br/memorandum/a20/ guimaraesmoreira01>.

20. Kroeff, P. (2008). Contribuicao da logoterapia no atendimento do individuo excepcional e de sua familia. Psico (Porto Alegre), 13(1), 164-173. 
21. Kroeff, P. (2011). Logoterapia: uma visão da psicoterapia. Revista Abordagem Gestalt, 17(1), 68-74. Recuperado em: 29 nov. 2012, de: <http://pepsic.bvsalud.org/scielo.php?script=sci_arttext\&pid=S1809-

$68672011000100010 \&$ lng $=p t \& n r m=$ iso $>$.

22. Kroeff, P. (2012). A pessoa com deficiência e o sentido da vida. Logos \& Existência,1(1), 58-64. Recuperado em 29 nov. 2012, de: <http:// www.ies.ufpb.br/ojs/index.php/le/article/view/12595/8046>.

23. Libardi, T. A. (2008). Dimensão da maturidade à luz da logoterapia. Teocomunicação (Porto Alegre), 38(159), 122-137 . Recuperado em 29 nov. 2012, de: <http://revistaseletronicas.pucrs.br/fo/ojs/index.php/teo/article/viewFile/4031/ 3079>.

24. Lima, A. B. \& Santa Rosa, D. O. (2008). O sentido de vida do familiar do paciente crítico. Revista da escola de enfermagem da USP, 42(3), 447453. Recuperado em 29 nov. 2012, de: <http://www.scielo.br/scielo.php? script $=$ sci_arttext\&pid $=$ S0080-62342008000300019\&Ing $=$ en\&nrm $=$ iso $>$.

25. Lima Neto, V. B. (2012). Morte e sentido da vida: Tanatologia e Logoterapia, um diálogo ontológico. Logos \& Existência, 1(1), 38-49. Recuperado em 29 nov. 2012, de:<http://www.ies.ufpb.br/ojs/index.php/le/article/view/12573/8044>.

26. Lukas, E. (1988). A logoterapia e suas possibilidades preventivas nas toxicomanias. Psico (Porto Alegre), 15 (1), 42-59.

27. Matos, D. C. (2012). Felicidade e sentido de vida na sociedade de consumo. Logos \& Existência, 1(1), 72-78. Recuperado em 29 nov. 2012, de: <http:// www.ies.ufpb.br/ojs/index.php/le/article/view/13782/8067>.

28. Milanesi, P. V. B. \& Amatuzzi, M. M. (2008). Os sentidos da liberdade segundo professores da educação básica. Psicologia da educação, 27, 115139. Recuperado em 29 nov. 2012, de: <http://pepsic.bvsalud.org/scielo.php? script $=$ sci_arttext\&pid $=$ S1414-69752008000200007\&lng=pt\&nrm=iso $>$.

29. Moreira, J. O.; Abreu, A. K. C. \& Oliveira, M. C. (2006). Moralidade e sociabilidade em Frankl: um norte para superação da violência. Psicologia em estudo. 11(3), 27-35. Recuperado em: 29 nov. 2012, de: $<$ http://www.scielo.br/scielo.php?script=sci_arttext\&pid=S1413-

$73722006000300019 \&$ lng $=$ en\&nrm $=$ iso $>$.

30. Moreira, N. \& Holanda, A. (2010). Logoterapia e o sentido do sofrimento: convergências nas dimensões espiritual e religiosa. Psico-USF, 15(3), 345356. Recuperado em 29 nov. 2012, de: <http://www.scielo.br/scielo.php? script=sci_arttext\&pid=S1413-82712010000300008\&lng $=$ en\&nrm=iso $>$.

31. Pereira, I. S. (2010). Mundo e Sentido na Obra de Viktor Frankl. Psico (Porto Alegre), 39(2), 159-165. Recuperado em 29 nov. 2012, de: <http:// revistaseletronicas.pucrs.br/ojs/index.php/revistapsico/article/viewFile/1507/

3696>.

32. Pereira, I. S. (2007). A vontade de sentido na obra de Viktor Frankl. Psicologia USP, 18(1), 125-136. Recuperado em 29 nov. 2012, de: <http:// www.revistasusp.sibi.usp.br/pdf/psicousp/v18n1/v18n1a07.pdf >.

33. Pettengill, M. A. M. \& Angelo, M. (2000). O sentido do cuidar da criança e da família na comunidade: a experiência de alunos de enfermagem. Revista da escola de enfermagem da USP, 34(1), 91-98. Recuperado em: 29 nov. 2012, de: <http:// www.scielo.br/pdf/reeusp/v34n1/v34n1a12.pdf >.

34. Rocha, E. F. \& Gomes, E. S. (2012). Autodistanciamento em Viktor E. Frankl a partir da compreensão de logos de Xavier Zubiri. Logos \& Existência, 1(1), 3849. Recuperado em 29 nov. 2012, de: <http://www.ies.ufpb.br/ojs/index.php/le/ article/view/12573/8044>.

35. Rodrigues, I. A. A. (2011). Paciente terminal: como dar sentido ao sofrimento diante da morte? Tema, 11(16). Recuperado em 29 nov. 2012, de: <http:// revistatema.facisa.edu.br/index.php/revistatema/article/view/74/82>. Rodrigues, L. A.; Barros, L. A. (2009). Sobre o Fundador da Logoterapia: Viktor Emil 
Frankl e sua contribuição à Psicologia. Estudos, 36(1/2), jan./fev. Recuperado em: 29 nov. 2012, de: <http://espiritualidadesentido.yolasite.com/resources/ sobre\%200\%20fundador\%20da\%20logoterapia.pdf>.

36. Roehe, M. V. (1998). Compreendendo grupos de auto-ajuda com o enfoque da logoterapia. Psico , 29(2), 165-171.

37. Roehe, M. V. (2005). Revendo idéias de Viktor Frankl no centenário de seu nascimento. Psico, 36(3), 311-314 set./dez. Recuperado em 29 nov. 2012, de: <http://revistaseletronicas.pucrs.br/revistapsico/ojs/index.php/revistapsico/article/ viewFile/1402/1102>.

38. Santa Rosa, D. O. \& Nascimento, T. C. (2010). O significado da personalidade profissional da enfermeira no bloco cirúrgico. Revista Baiana de Enfermagem, 19, 63-73. Recuperado em 29 nov. 2012, de: <http://www.portalseer.ufba.br/ index.php/enfermagem/article/view/3891/2854>.

39. Santos, G. A. O. (1999). De Viktor Frankl à pós-modernidade: sobre a ética dos campos de concentração. Psique, 9(15), nov.

40. Santos, R. R. P. dos. (1984). Considerações sobre a loucura. Jornal brasileiro de Psiquiatria , 1(33), 39-44.

41. Seibt, C. (2006). O Sentido da vida e a terceira idade. Ideação, 8(8), 121136. Recuperado em 29 nov. 2012, de: <http://e-revista.unioeste.br/index.php/ ideacao/article/view/844/713>.

42. Silva, J. P.; Damasio, B. F.; Melo, S. A. (2009). O sentido de vida e o estresse do professorado: um estudo correlacional. Caderno de psicologia social de do trabalho, 12(1), 111-122. Recuperado em 29 nov. 2012, de: <http://pepsic.bvsalud.org/scielo.php?script=sci_arttext\&pid=S1516-

$37172009000100009 \&$ Ing $=$ pt\&nrm $=$ iso $>$.

43. Silva, L. B. (2012). Sobre o consumo e o consumismo: a consumação do vazio. Logos \& Existência, 1(1), 79-87. Recuperado em 29 nov. 2012, de: <http:// www.ies.ufpb.br/ojs/index.php/le/article/view/13270/8068>.

44. Silveira, D. R.; Mahfoud, M. (2008). Contribuições de Viktor Emil Frankl ao conceito de resiliência. Estudos de psicologia, 25(4), 567-576. Recuperado em 29 nov. 2012, de: <http://www.scielo.br/scielo.php?script=sci_arttext\&pid=S0103$166 \times 2008000400011 \&$ lng $=$ en\&nrm $=$ iso $>$.

45. Solymos, G. M. B. (2006). A centralidade da pessoa na intervenção em nutrição e saúde. Estudos avançados,20 (58), 109-122. Recuperado em 29 nov. 2012, de: <http://www.scielo.br/scielo.php?pid=S010340142006000300013\&script $=$ sci_arttext $>$.

46. Sommerhalder, C. (2010). Sentido de vida na fase adulta e velhice. Psicologia: reflexão e crítica, 23(2), 270-277. Recuperado em: 29 nov. 2012, de: <http://www.scielo.br/scielo.php?script=sci_arttext\&pid=S0102$79722010000200009 \& \operatorname{lng}=$ en\&nrm $=$ iso $>$.

47. Souza, E. A.S. \& Gomes, E. S. (2012). A visão de homem em Frankl. Logos \& Existência, 1(1), 50-57. Recuperado em 29 nov. 2012, de: <http:// www.ies.ufpb.br/ojs/index.php/le/article/view/12630/8064>.

48. Xausa, I. A.M. (1983). Victor Frankl: um psicólogo no campo de concentração. Psico (Porto Alegre), 6(2), 95-115. 